\title{
Nuevas tendencias en la enseñanza del Derecho: la destreza legal
}

Shoschana Zusman

Razones profesionales me llevaron en el curso de este año a seguir de cerca un juicio ante un juez comercial en la High Court of Justice en Londres. Ello supuso asistir durante dos semanas a audiencias en las que los barristers, abogados de corte, examinaron a los testigos, presentaron sus alegatos y obtuvieron el pronunciamiento del juez.

La experiencia fue sin duda interesante, pero si hubo algo destacable y singular, fue la calidad profesional de abogados y jueces. Los abogados conocían el caso en detalle, manejaban el expediente con precisión, sus respectivos discursos, además de estar impecablemente estructurados, expresaban un razonamiento jurídico acabado, controlaban con maestría su expresión corporal, su tono de voz acompañaba perfectamente al discurso, manifestaban en todo momento genuina consideración por el valor del tiempo del juez y, en consideración a ello, lo inducían a revisar los documentos verdaderamente importantes, sin expresiones inútiles ni pérdida de tiempo.

El juez, por su parte, seguía con atención el desarrollo del debate, hacía las preguntas que le permitían despejar dudas, leía con atención los documentos que las partes le sugerían leer; interrogaba a los testigos y discutía con las partes cuestiones no sólo referidas al fondo del asunto sino a la mecánica de las audiencias mismas como, por ejemplo, el número de sesiones que serían necesarias o el tiempo que había que conceder a cada testigo. Vencido el plazo fijado para la terminación de las audiencias, el juez, quien, a esas alturas ya conocía el expediente a la perfección, resolvió la controversia. Y lo hizo de manera directa y precisa, con criterio comercial, imponiendo una solución justa y equitativa. 
El efecto que en términos de eficiencia social tiene un sistema de solución de controversias semejante, no requiere mayor comentario. ¿Qué hace -me preguntaba- que el desempeño de todos los actores del proceso sea tan profundamente racional?

Existen sin duda, muchas respuestas válidas y no necesariamente excluyentes entre sí. Pero una de las razones de ese acabado nivel de desarrollo está, sin duda, en la enseñanza del Derecho.

Durante los últimos cincuenta años la mayoría de las escuelas de Derecho norteamericanas e inglesas vienen discutiendo el tema de la metodología de enseñanza del Derecho. Fruto de ese debate ha sido el surgimiento de una corriente orientada hacia la educación a través del desarrollo de destrezas, conocida como el Skill movement for education in law.

Los primeros intentos de reforma legal se ubican en Estados Unidos en 1945 con el clinical movement, que comenzó a dar importancia a la práctica preprofesional a través de clínicas legales. Las clínicas revelaron prontamente su insuficiencia y fueron dando paso a cursos de entrevistas a clientes, para desembocar en cursos de razonamiento legal e interpretación de la ley. Más recientemente, la atención ha estado puesta en el desarrollo de un amplio abanico de competencias profesionales, habiéndose acuñado la expresión drain skills: drafting (redacción); research (investigación); advocacy (defensa); interviewing (entrevistas) y negotiation (negociación). Esta corriente ha sido ya acogida por la barra inglesa en el año 1989 y por Law Society en el año 1993 y hoy nadie discute que «destreza legal» (legal skills) es una línea de carrera que debe ser incorporada al currículo.

Pero, ¿qué y para qué los cursos de destreza legal? Señala Barnett ${ }^{1}$ que en la sociedad contemporánea, el conocimiento se define a través de los conceptos de habilidad, competencia, resultados, aprendizaje experimental, capacitación o empresa que, tomados en conjunto, son indicadores de que las definiciones tradicionales de conocimiento son inadecuadas para responder a los problemas de la sociedad contemporánea. Como resultado de ello, hoy se requiere una educación más profesional que académica; necesariamente interdisciplinaria; y un

1 R.Barnett; The limits of competence: Knowledge, Higher Education and Society; 1994. 
aprendizaje basado en competencias y orientado a la solución de problemas.

Esta tendencia aparece claramente recogida en la agenda para el sector Educación del Reino Unido -Higher Education Meeting the Challenge- (1987) donde se plantea que la educación debe servir a las necesidades de la economía, asegurando a los graduandos no sólo su formación para el empleo sino para adquirir la capacidad de estudiar y desarrollarse; para cambiar con el cambio de las organizaciones y para estar preparado a romper los moldes del pasado. Otros programas, como el Training Agency's Enterprise in Higher Education Programme, proponen como meta fundamental el lograr estudiantes más autónomos y con autoresponsabilidad de seguir educándose a lo largo de su vida. ${ }^{2}$

Hoy existe conciencia de la necesidad de desarrollar habilidades para aprender de la experiencia, asimilar rápidamente gran cantidad de información, analizar las cosas desde diversas perspectivas, desarrollar capacidades comunicativas (presentaciones orales, reportes escritos, un idioma extranjero) y desarrollar cualidades personales («drive», autoadministración, manejo del tiempo, habilidad para trabajar sin necesidad de supervisión, iniciativa, trabajo en equipo, solución de problemas, análisis de riesgo/costo/beneficio, entre otras). Hoy existe también conciencia de que el método de enseñanza que funda su contenido en la transmisión de conocimientos, es insuficiente porque abarca una porción mínima del conocimiento, el alumno olvida con facilidad lo que ha estudiado, lo aprendido se convierte rápidamente en obsoleto debido a los cambios en la sociedad y porque al no estar orientada a la solución de problemas, la comprensión del tema resulta siendo superficial.

Y específicamente en el ámbito de la enseñanza del Derecho, se comienza a postular que en ésta, lo académico y lo profesional deben estar unidos. Es interesante mencionar la encuesta formulada a 112 firmas de abogados en el Reino Unido, donde se les preguntó de qué carecían los abogados principiantes. Ninguna respuesta aludió al co-

Referencias tomadas de Andy Boon; Skills in the initial stage of legal education: theory and practice por transformation; en Teaching Lawyer Skills, edited by Julian Webb and Caroline Maughan. 
nocimiento sino, en cambio, a la habilidad para relacionarse con otros, a la necesidad de independencia, de confianza en sí mismos y de buen juicio. La mayor parte de los encuestados reclamó una mejor formación en áreas tales como comunicación con el cliente, comunicación en general, relaciones con el staff, redacción, negociación, manejo del tiempo e independencia.

A partir de las necesidades descritas, las escuelas de Derecho anglosajonas han diseñado una amplia gama de métodos de enseñanza de habilidades legales. Uno de los más interesantes es el método holístico, que, en oposición al atomístico, induce al alumno a aproximarse a los problemas integrando las dimensiones del conocimiento legal y extralegal y a unir el mundo del puro entendimiento con el de la acción. O dicho de otra manera, integrando el mundo de la acción al de los valores académicos tradicionales de comprensión, crítica, interdisciplina y sabiduría. Se trata de un método concentrado en el alumno (y no en el maestro) que «integra un rango muy amplio de habilidades, como son el razonamiento legal, el análisis de casos jurisprudenciales y doctrinarios, habilidades de defensa oral y escrita, responsabilidad profesional, sentido de ética legal, sensibilidad frente a los hechos, capacidad de reunión de hechos, análisis costo-beneficio, prueba de hipótesis, comprensión de la vinculación entre el Derecho y los hechos, habilidad para proyectar ideas, sentido común, juicio, destreza para trabajar con otros bajo esquemas de colaboración y una gama de habilidades interpersonales: saber escuchar, ser empático y poder integrar la mente a los afectos. ${ }^{3}$ "

Las clases de Legal Skills se desarrollan en sesiones prácticas, donde se focaliza el análisis en el desarrollo de habilidades de trabajo en equipo buscando que el alumno descubra desde el inicio de su carrera, la diferencia existente entre el "cielo de conceptos" y uel pantano de problemas" y que se capacite en el manejo conjunto de los mismos, a fin de aproximarse al problema -y resolverlo- de manera integral. A través de ejercicios simples, muchos de ellos no legales, el profesor va describiendo posibles escenarios de acción de los abogados: la corte, la oficina de abogados, una dependencia pública, donde se plantea un tipo de problemas que los abogados en ejercicio definitivamente afron-

3 Schneider, citado en Ibidem; p.111. 
tan y que lleva a los alumnos a adquirir la convicción de que para resolver un caso, el conocimiento legal es sólo uno de los aspectos a enfrentar. El método se apoya en buena medida en proyección de videos sobre, por ejemplo, informes en la Corte, que los alumnos deben comentar, recurriéndose muy frecuentemente a la técnica de la simulación de casos y hasta a presentaciones teatrales que permitan al alumno descubrir fortalezas y debilidades. Se recomienda a los alumnos llevar un diario, donde deben anotar todo lo que piensan en relación a los ejercicios puestos en práctica, incluyendo el análisis de sus propios sentimientos y percepciones sobre cada uno de los temas tratados en clase.

Un ejercicio que se emplea para crear en los alumnos la sensación de "pantano de problemas», entrenándolos en el manejo de situaciones imprevistas, es la simulación del caso en que un cliente se presenta en la oficina del abogado y el practicante debe poder decirle que el texto del contrato que le pidió preparar, todavía no está listo. La dinámica que se establece a partir de la simulación del caso y las conclusiones sobre la buena o mala performance de los actores, constituyen instrumentos utilísimos en su futuro desempeño profesional, pues les permite reparar en la importancia del tema y analizar, a través de la actuación de los otros, sus propias capacidades y dificultades en el manejo de situaciones semejantes.

Un ejercicio que pretende capacitar al alumno en la técnica de analizar el problema en su integridad consiste en simular el caso de un contrato, en donde ambos contratantes lo interpretan en sentido distinto. Aquí el asunto no se reduce a dar respuesta legal al significado del contrato -aun cuando se pasa por ello- sino a plantear una estrategia basada en el costo-beneficio para el cliente y, de acuerdo a ello, «recomendar » el mejor curso de acción. En este tipo de ejercicios, el problema es evaluado de manera integral, tomándose en consideración todos sus elementos, que van desde la interpretación del contrato, hasta las reales posibilidades de ganar un hipotético juicio, su tiempo de duración, el monto involucrado, el significado del mismo para el cliente y la opción de una negociación. Y en el camino se induce al alumno a preguntarse por las percepciones y sentimientos que la situación les provoca: pena, rabia, simpatía, antipatía, llegándose a la conclusión de que un mal manejo de los afectos puede ser funesto para el resultado de un caso. En discusiones de este tipo, aparecen como ver- 
daderas necesidades, tener que ingresar al ámbito de la economía, de las finanzas, del comercio, de las relaciones interpersonales (i.e. "no todos los socios quieren lo mismo") y hasta de la ética profesional, pues los estudiantes se plantean, por ejemplo, el dilema de que el mejor consejo para el cliente puede ser el peor negocio para el abogado.

Para el desarrollo del razonamiento legal, la metodología holística propone el ejercicio de "Perdí mi billetera» donde los alumnos deben poner por escrito todos los pasos que consideren necesarios para resolver ese problema. Eso los obliga a pensar ordenadamente a partir de un problema cotidiano, a buscar alternativas, a evaluarlas, a planificar la acción más eficiente, imaginando en el camino, todos los problemas que enfrentará. ¿ No consiste finalmente en eso el trabajo profesional? Ejercicios como el descrito permiten ingresar con facilidad al terreno del razonamiento legal, pues a esas alturas los estudiantes han entendido que lo primero es identificar y diagnosticar el problema; lo segundo, generar alternativas de solución; lo tercero desarrollar un plan de acción, listando y «rankeando" las posibles alternativas; y lo último, implantar y evaluar permanentemente el plan hasta obtener el resultado propuesto. Luego se enseña cada paso del proceso, donde existen técnicas específicas para, por ejemplo, reunir información; manejarla eficientemente (a través de flujos y mapas); generar hipótesis $\mathrm{y}$, finalmente, evaluarlas y desarrollarlas, incluyendo el análisis de las pruebas.

En el tema de negociación, por ejemplo, se forman grupos de 5 ó 6 alumnos quienes deben simular ser una familia que apostó en conjunto al juego de lotería y ganó. La familia discute qué hacer con el premio, asignándose a cada miembro la defensa de un determinado interés: el del padre, guardar el dinero para la educación de los hijos; el de la madre, invertirlo en la mejora de la casa; el del hijo, comprarse un automóvil y el de la hija, salir todos juntos de vacaciones. El imperativo es que cada "familia" discuta, negocie y llegue a un acuerdo en un tiempo determinado. No parece existir un mecanismo más simple y a la vez más eficiente de mostrar en los hechos la complejidad de una negociación, los intereses contrapuestos, los conflictos interpersonales, el análisis riesgo/beneficio y las técnicas específicas para alcanzar acuerdos satisfactorios.

Y para "aprender a vivir en el pantano", resultan claves dos reglas. La primera es la de «desideologización» del Derecho, que parte de la 
premisa de que aun cuando el Derecho pueda ser definido según diversas corrientes de pensamiento, éste es, fundamentalmente, una herramientas que permite a los abogados resolver los retos y problemas que la profesión les impone a diario. En esa línea, se plantea a los alumnos la pregunta de cuál es su ideal como futuro abogado. Si la respuesta es «quiero ayudar a los desafortunados» o «quiero logar la libertad y la justicia para todos» o «busco reivindicar el derecho de los oprimidos" el texto plantea, no sin humor por cierto, que lo mejor es que postule al Cuerpo de Paz y no a una escuela de Derecho. Esta postura supone una propuesta de valores alternativos, absolutamente concretos, aunque no por ello menos éticos, como son el mantener estándares elevados de competencia; dar el mejor servicio al cliente o conseguir que los jueces administren una verdadera justicia.

La segunda regla es la de la enseñanza client oriented que induce al estudiante a plantearse los problemas legales, no en abstracto, sino a partir de las necesidades del cliente. Ello implica abandonar el análisis legal meramente especulativo y adoptar uno que se inicia en la toma de posición de acuerdo a las necesidades del cliente, exactamente de la misma manera como ocurre en la práctica profesional. En ese contexto, la pregunta sobre, por ejemplo, la toma de partido por la posición objetiva o subjetiva sobre el error en el objeto, o la teoría más convincente sobre la lesión, no es que sean irrelevantes sino que tienen valor en tanto sean útiles a las necesidades del cliente. Lo cual revela también, una idea del Derecho como disciplina esencialmente argumentativa, donde no hay verdades ni mentiras sino defensa de los intereses del cliente, en el contexto de ciertas reglas de juego y, naturalmente, dentro de los cánones éticos más estrictos.

Hay mucho más sobre el tema y bien vale la pena que las facultades de Derecho aborden la discusión sobre el aprendizaje a través del desarrollo de habilidades, no sólo por su decisiva contribución a la eficiencia institucional sino porque el postular que las personas no nacen con «rapidez», «habilidad", "talento», «labia" o «brillantez» sino que son "dones adquiribles" en el proceso de su formación como abogados, convierte a la enseñanza del Derecho en una actividad profundamente democrática e integradora. 